\title{
BMJ Open Prevalence and characteristics of chronic fatigue syndrome/myalgic encephalomyelitis (CFS/ME) in Poland: a cross-sectional study
}

\author{
Joanna Słomko, ${ }^{1}$ Julia L Newton, ${ }^{2}$ Sławomir Kujawski, ${ }^{1}$ Małgorzata Tafil-Klawe, ${ }^{3}$ \\ Jacek Klawe, ${ }^{1}$ Donald Staines, ${ }^{4}$ Sonya Marshall-Gradisnik, ${ }^{4}$ Pawel Zalewski ${ }^{1}$
}

To cite: Słomko J, Newton JL, Kujawski S, et al. Prevalence and characteristics of chronic fatigue syndrome/ myalgic encephalomyelitis (CFS/ME) in Poland: a crosssectional study. BMJ Open 2019;9:e023955. doi:10.1136/ bmjopen-2018-023955

- Prepublication history for this paper is available online. To view these files, please visit the journal online (http://dx.doi. org/10.1136/bmjopen-2018023955).

Received 4 May 2018 Revised 19 December 2018 Accepted 8 January 2019

Check for updates

(C) Author(s) (or their employer(s)) 2019. Re-use permitted under CC BY-NC. No commercial re-use. See rights and permissions. Published by BMJ.

${ }^{1}$ Department of Hygiene, Epidemiology and Ergonomy, Uniwersytet Mikolaja Kopernika Collegium Medicum, Bydgoszcz, Poland

${ }^{2}$ Institute for Cellular Medicine, Newcastle University, Newcastle, UK

${ }^{3}$ Department of Human Physiology, Uniwersytet Mikolaja Kopernika Collegium Medicum, Bydgoszcz, Poland

${ }^{4}$ Medical Sciences, Griffith

University, Southport,

Queensland, Australia

Correspondence to

Prof Pawel Zalewski;

p.zalewski@cm.umk.pl

\section{ABSTRACT}

Objectives The aim of this study was to estimate the prevalence of chronic fatigue syndrome/myalgic encephalomyelitis (CFS/ME) and describe illness characteristics in a community population in Poland. Design: cross-sectional study.

Setting Poland.

Participants Of the cohort of 1400 who self-presented with fatigue only 69 subsequently were confirmed as having CFS/ME using the Fukuda criteria.

Main outcome measures Participants completed the following screening symptom assessment tools: Chalder Fatigue Scale, Hospital Anxiety and Depression Scale (HADS), Epworth Sleepiness Scale (ESS), Composite Autonomic Symptom Score 31 (COMPASS 31), Quality of Life Scale (QOLS). Haemodynamic and autonomic parameters were automatically measured at rest with a Task Force Monitor. Results In 1308, from 1400 (93\%) individuals who identified themselves as fatigued, recognised chronic conditions were identified, for example, neurological $(n=280,21.5 \%)$, neurodegenerative $(n=200,15 \%)$, psychiatric $(n=654,50 \%)$ and immunologic $(n=174$, $13.5 \%$ ) disorders. The remaining 69 participants (mean age 38.3 \pm 8.5 ) met the Fukuda defintion for CFS/ME and had baseline objective assessment. The majority had experienced symptoms for over 2 years with $37 \%$ having symptoms for $2-5$ years and $21.7 \%$ for more than 10 years. The COMPASS 31 indicated that $50 \%$ have symptoms consistent with orthostatic intolerance. About 43/69 (62\%) had Epworth sleepiness scores $\geq 10$, ie, consistent with excessive daytime sleepiness, 26/69 $(38 \%)$ had significant anxiety and 22/69 (32\%) depression measured by HADS A \& D. Quality of life is significantly impaired in those with Fukuda criteria CFS (QLS score $64 \pm 11$ ) with significant negative relationships between quality of life and fatigue $(p<0.0001)$, anxiety $(p=0.0009)$, depression $(p<0.0001)$ and autonomic symptoms $(p=0.04)$. Conclusion This is the first study to summarise illness characteristics of Polish CFS/ME patients. Our study has confirmed that fatigue is a common and under-recognised symptom affecting the Polish population.

\section{INTRODUCTION}

Diagnostics and treatment of the chronic fatigue syndrome/myalgic encephalomyelitis
Strengths and limitations of this study

This is the first study to summarise illness characteristics of a cohort of Polish chronic fatigue syndrome/ myalgic encephalomyelitis (CFS/ME) patients.

- We used Fukuda criteria to indicate patients with CFS/ME.

- Recruitment was based on self-identification in response to an advertisement in CFS/ME community support networks across Poland

- Methodologically, more robust epidemiological studies of fatigue and its consequences in the Polish population are now needed.

(CFS/ME) present a challenge to specialists as this syndrome is not a clearly identified, uniform disease but a set of symptoms resembling those occurring in other diseases, in which a sense of chronic fatigue predominates. In some countries (eg, Poland), CFS/ ME is diagnosed very rarely, which may be associated with the fact that the aetiology of the disease is still poorly known, and with diagnostic problems resulting from a lack of detailed and uniform guidelines allowing an unambiguous diagnosis and initiation of effective treatment in CFS/ME patients.

The available studies provide several diagnostic criteria based on a definition of the American Centers for Disease Control (CDC), the Oxford Criteria, or the Canadian Guidelines. Criteria proposed by CDC (Fukuda et al. 1994) are most commonly used as acceptable diagnostic criteria when recruiting CFS/ ME patients for scientific studies. However, they are encumbered by several disadvantages (eg, fatigue experienced for at least 6 months), which-from the point of view of clinical practice-may delay a diagnosis in patients who do not meet this criterion precisely. The Oxford criteria propose a new diagnostic approach, focusing mainly on an 
aspect of mental rather than somatic fatigue. The Canadian criteria (CDC) expand the CFS/ME definition with additional diagnostic criteria, ie, postexertional malaise and presence of neurological, endocrine, cognitive and autonomic (orthostatic intolerance) disorders. The proposed CFS/ME definition, including malaise and symptoms exacerbation after exercise, allows differentiating CFS/ME patients from patients with depression or fibromyalgia. Alternative criteria, such as the International Consensus Criteria, disclose a further range of symptoms pertaining to the neurological, immunological, gastrointestinal and autonomic systems.

Its global prevalence, ranging between $0.4 \%$ and $2.5 \%$, is growing; most commonly, it is observed in the group of 20-40 year olds, more frequently in professionally active women. CFS/ME is considered to be a common condition in countries such as the UK, Australia and the USA. ${ }^{12}$ In the UK, it affects up to 250000 individuals with frequencies reported of up to $0.2 \% .^{3}$ In the UK, Fukuda-defined cases have a prevalence of $0.2 \%$. In the USA, the prevalence of Fukuda-defined cases has been reported between $0.2 \% 5 \%$ and $0.4 \%$. Finding from the Australian cohort showed that from 535 patients diagnosed with CFS/ME by a primary care physician, $30.28 \%$ met Fukuda criteria. To date CFS/ME has neither been reported in Poland, nor its prevalence defined. There are currently no CFS/ ME clinical services.

The aim of this study was to summarise sociodemographic and illness characteristics in those reporting CFS/ME symptoms in a Polish population. We set out to define the presence and characteristics of CFS/ME in Poland in order to identify a cohort of those patients who could potentially participate in further research studies.

\section{METHODS}

\section{Setting}

This study took place from March 2014 till July 2016.

\section{Participants}

Recruitment was based on self-identification in response to an advertisement in CFS/ME community support networks across Poland, as well as a general advertisement on local radio and social media.

Initially any individuals willing to participate were directed to a phone line. Within days of setting up the phone line, it became clear that this mechanism to identify and recruit potential participants would be overwhelmed. The team therefore directed all potential participants to a website where more information about the study was available and where individuals were invited to self-complete the Fukuda criteria online. If individuals, on completing the online scoring, felt that they met the Fukuda criteria ${ }^{4}$ within 7 days they were invited to attend the research facility. To be eligible for this study, participants were required to (1) meet Fukuda criteria, (2) be between 25 and 65 years of age and (3) be a resident of Poland. The identification process is shown in figure 1 .

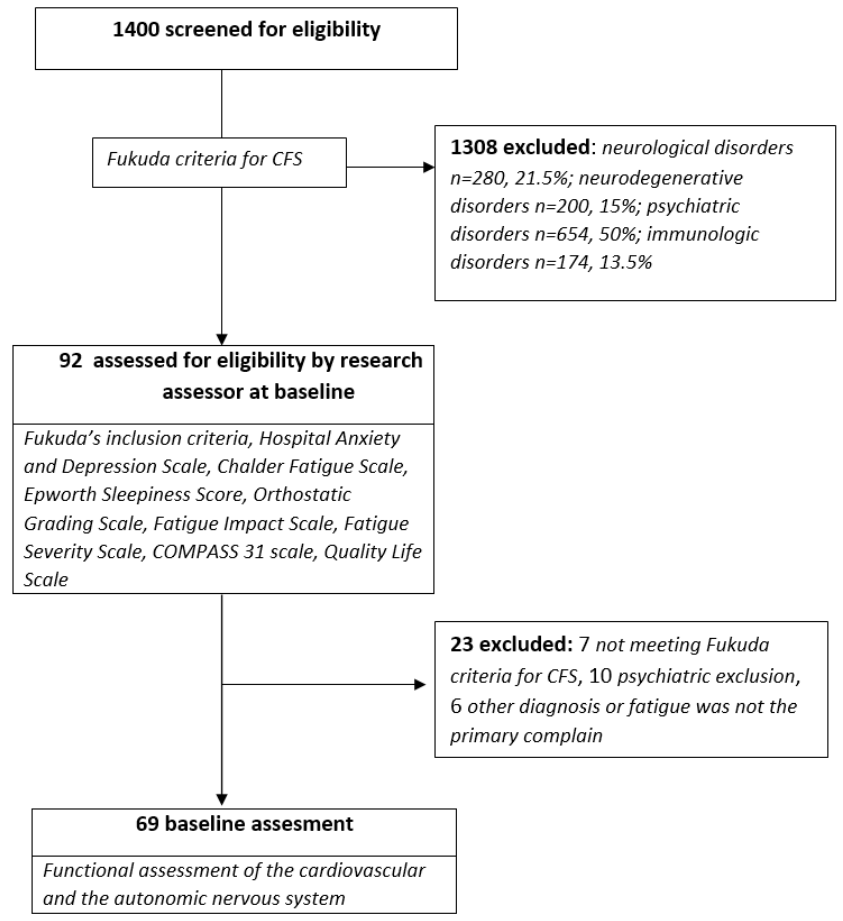

Figure 1 Study protocol.

Patient and public involvement

Patients were not involved in the design of this study. Results from the current study will be disseminated to participants through newsletters in layman terms. We will also communicate our results through a number of other scientific and non-scientific channels including presentations at relevant congresses or in relevant fora.

\section{Clinical assessment}

Those who fulfilled the eligibility criteria for Centers for Disease Control and Prevention (Fukuda) were invited to attend the research unit at the chronobiology laboratory (windowless and sound-insulated room, temperature $22^{\circ} \mathrm{C}$, humidity $60 \%$ ). They were seen by members of the research team in an assessment that took place over $40 \mathrm{~min}$. Individuals participated in a standardised baseline assessment which comprised a battery of symptom assessment tools. Those screened as fulfilling criteria for $\mathrm{CFS} / \mathrm{ME}^{4}$ were also reviewed clinically by a member of the research team in order to determine whether their symptoms were consistent with these criteria, that there were no psychiatric exclusions or other diagnoses that could be associated with CFS/ME or where fatigue was not the primary complaint. Sixty-nine individuals subsequently went on to have a further baseline objective assessment.

\section{Symptom assessment tools}

Participants completed the following screening symptom assessment tools: Chalder Fatigue Scale, ${ }^{5-7}$ Hospital Anxiety and Depression Scale (HADS) ${ }^{8}$ Epworth Sleepiness Scale (ESS), ${ }^{9}$ Composite Autonomic Symptom Score 31 (COMPASS 31) and ${ }^{10} 11$ Quality of Life Scale (QOLS). ${ }^{10-14}$ 
Functional assessment of the cardiac and autonomic nervous system

Cardiovascular and autonomic nervous system measurements were performed with a dedicated high-tech deviceTask Force Monitor (TFM, CNSystems, Medizintechnik, Graz, Austria). The main area of TFM application is beatto-beat analysis of heart rate (ECG) oscillometric and non-invasive continuous blood pressure measurements (oscBP, contBP) and impendance cardiography. ${ }^{15-22} \mathrm{~A}$ detailed of study protocol and its methodology have been presented in our previous articles. ${ }^{23} 24$

In all cases TFM measurements were performed during 10 min of supine rest (phase I) and subsequently asked to standing (phase II) during which changes in heart rate were assessed and where haemodynamic changes were consistent with recognised consensus criteria for a diagnosis of postural tachycardia syndrome (PoTS) made. ${ }^{25}$

We classified each individual's autonomic function profile into sympathetic or parasympathetic dominant according to their sympathetico-vagal balance during 10 min of supine rest. This was based on previous studies and assessed using the LF/HF ratio which was considered to suggest a sympathetic dominant pattern if $\mathrm{LF} / \mathrm{HF}$ was $>1$ and parasympathetic if the ratio was $<1 .^{26} 27$

\section{Statistical analyses}

Statistical characteristics of measured values were presented as arithmetic means and $\pm \mathrm{SD}$. The normality of continuous variables distribution was evaluated with the Shapiro-Wilk test depending on distribution characteristics of analysed variables, the independent samples Student's t-test or the Mann-Whitney U test was used to evaluate significance of differences between measured values obtained in the group of each phenotypes. All calculations were performed with the package Statistica V.13.0 (StatSoft), with the assumed level of statistical significance of $\alpha<0.05$.

\section{RESULTS \\ Recruitment of the cohort-the prevalence of fatigue in a Polish population}

During the media campaign, 1400 individuals identified themselves to the research team as fitting, they believed, the criteria for CFS/ME. One thousand and three hundred eight of those subsequently were found not to meet the Fukuda criteria for CFS/ME.

In the $1308(93 \%)$ individuals who identified themselves as fatigued, recognised chronic conditions were identified. These were conditions associated with the symptom of fatigue and therefore could have been the attributable cause for their fatigue symptoms (and therefore not consistent with the Fukuda diagnostic criteria). These fatigue associated conditions were broadly classified into conditions that were: neurological $(n=280,21.5 \%)$, neurodegenerative $(\mathrm{n}=200,15 \%)$, psychiatric $(\mathrm{n}=654$, $50 \%)$ and immunologic $(\mathrm{n}=174,13.5 \%)$ disorders.

\begin{tabular}{lrc}
\hline $\begin{array}{l}\text { Table } 1 \text { Other symptoms reported at initial assessment, N } \\
=69\end{array}$ & No & $\%$ \\
\hline Specific symptom & 12 & 17.7 \\
\hline IBS & 17 & 24.6 \\
\hline Migraine & 8 & 11.6 \\
\hline Seasonal allergy & 40 & 58.1 \\
\hline Slight food intolerance/nausea/alcohol intolerance & 13 & 18.8 \\
\hline Back pain & 9 & 13.0 \\
\hline Tinnitus & 9 & 13.0 \\
\hline Palpitations with no cardiac history & 8 & 11.6 \\
\hline Periodical fever & 0 & 0 \\
\hline Sensory disturbances & 15 & 21.7 \\
\hline Chest symptoms with no medical history & 30 & 43.5 \\
\hline Mood fluctuations & 41 & 59.4 \\
\hline Chronic stress & 34 & 49.3 \\
\hline Overworked/work stress & 0 & 0 \\
\hline Shift work & 3 & 4.3 \\
\hline Care work & 7 & 10.1 \\
\hline Newborn care & 9 & 13.0 \\
\hline Frequent infections & 22 & 31.9 \\
\hline Night hyperhidrosis & 28 & 40.6 \\
\hline Sleep disturbance/hypersomnia & 3 & 4.3 \\
\hline Unexplained anxiety & 10 & 14.5 \\
\hline Sensory disturbance & & \\
\hline & & \\
\hline
\end{tabular}

Characteristics of a polish cohort of CFS/ME patients meeting the Fukuda criteria

Of the total group with CFS/ME, 41 were female (59.4\%). The majority of individuals had a normal BMI (58\%) with $24(35 \%)$ being considered overweight and $3(4.3 \%)$ being obese. Two individuals $(2.9 \%)$ were considered underweight. The majority of individuals were considered to be of a specialist professional group (engineers).

\section{Symptom burden of a polish cohort of CFS/ME patients meeting the Fukuda criteria}

The majority of those with CFS/ME had had symptoms for over 2 years with $37 \%$ having symptoms for $2-5$ years and $21.7 \%$ having symptoms for more than 10 years. The vast majority described unrefreshing sleep with impaired short-term memory and concentration (91.3\%), postexertional malaise $89 \%$, multi-joint pain without swelling or redness $72.5 \%$, headaches $62.3 \%$, muscle pain $66.7 \%$, sore throat $39.1 \%$ and tender cervical or axillary lymph nodes $30.4 \%$.

Table 1 shows the prevalence of other symptoms identified in those found to have Fukuda CFS/ME. This illustrates the fact that many clinical specialists may come into contact with individuals who may subsequently be identified as having CFS/ME. When COMPASS 31 scores were considered these are shown in table 2 with $50 \%$ of individuals with $\mathrm{CFS} / \mathrm{ME}$ having symptoms consistent with orthostatic intolerance. HAD scores were high for both 
Table 2 Composite Autonomic Symptom Score 31Autonomic symptoms, $\mathrm{N}=69$

\begin{tabular}{lll}
\hline Specific symptom & No & $\%$ \\
\hline Orthostatic intolerance & 40 & 50.0 \\
\hline Dizziness/headaches & 41 & 59.4 \\
Sudden paleness & 25 & 36.2 \\
\hline Arrhythmia & 29 & 42.0 \\
\hline Dryness eyes mouth & 45 & 65.2 \\
\hline Vasomotor & 24 & 34.8 \\
\hline Secretomotor & 30 & 43.5 \\
Upper gastrotract symptoms & 38 & 55.1 \\
Unknown gastropain & 26 & 37.7 \\
Constipation & 21 & 30.4 \\
Diarrhoea & 28 & 40.6 \\
Urinary & 21 & 30.4 \\
Sexual failure & 19 & 27.5 \\
Sleep & 68 & 98.5 \\
Pupilomotor & 28 & 40.6 \\
Anxiety & 34 & 49.3 \\
\hline
\end{tabular}

anxiety and depression and 43/69 (62\%) were found to have ESS scores $\geq 10$, ie, consistent with excessive daytime sleepiness. Considering scores from HADS A \& D, 26/69 $(38 \%)$ had scores consistent with significant anxiety and 22/69 (32\%) depression.

Quality of life of a polish cohort of CFS/ME patients meeting the Fukuda criteria

Quality of life scores assessed using the QOLS were mean (SD) 64 (11). This confirmed that quality of life is significantly impaired in those with Fukuda criteria CFS/ME and well below the expected for a healthy population. When we considered the relationship between quality of life and the other symptoms frequently seen in those with CFS/ME, there were strong significant negative relationships between quality of life and fatigue $(p<0.0001)$,
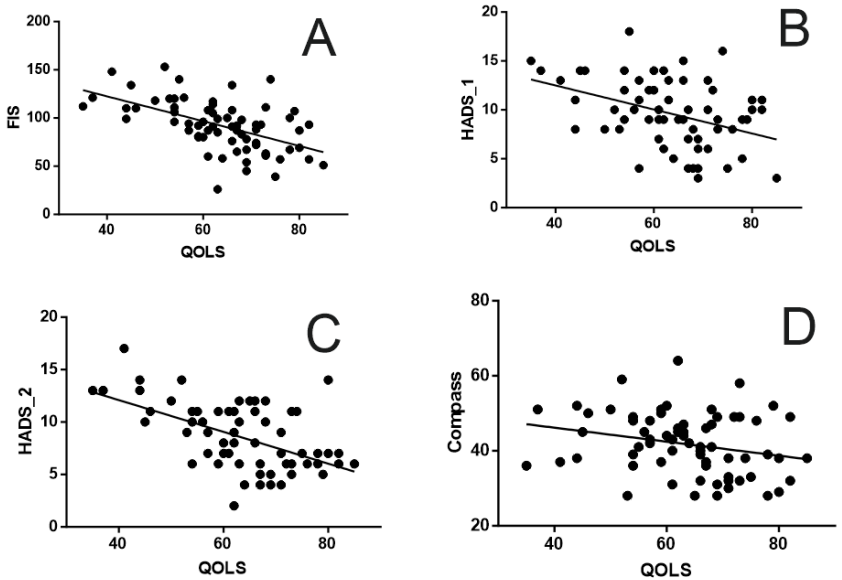

Figure 2 The relationship between quality of life measured using the QOLS scale and (A) fatigue severity assessed using the fatigue impact scale $(B)$ anxiety measured using the HADS Anxiety Scale (HADS-1) (C) depression measured using the HADS Depression Scale (HADS-2) and D) autonomic symptom burden measured using the COMPASS 31.

anxiety $(\mathrm{p}=0.0009)$, depression $(\mathrm{p}<0.0001)$ and autonomic symptoms $(\mathrm{p}=0.04)$, figure 2 . There were no significant relationships between age or daytime sleepiness.

\section{Autonomic function in a polish cohort of CFS/ME patients} meeting the Fukuda criteria

When we classified the cohort according to predominance of sympathetic or parasympathetic function, 44/69 (64\%) were found to be sympathetic predominant and 25 parasympathetic. When we considered symptom burden between these two phenotypes, there were no significant differences in symptoms or impact on quality of life between the groups (table 3). At rest, the sympathetic predominant group had significantly higher heart rate, ER and LF HRV and reduced LVET, PEP and HF HRV compared with the parasympathetic group. The total PSD was comparable between groups however sympatheticovagal balance was different between the

Table 3 Baseline quality of life scores, $N=69$

\begin{tabular}{|c|c|c|c|c|c|c|c|}
\hline \multirow[b]{2}{*}{ Variable } & \multicolumn{2}{|c|}{ Total group } & \multicolumn{2}{|c|}{$\begin{array}{l}\text { Sympathetic dominant } \\
(n=44)\end{array}$} & \multicolumn{2}{|c|}{$\begin{array}{l}\text { Parasympathetic } \\
\text { dominant }(n=25)\end{array}$} & \multirow[b]{2}{*}{$P$ value } \\
\hline & Mean & SD & Mean & SD & Mean & SD & \\
\hline Chalder Fatigue Scale & 25.3 & 3.7 & 25.5 & 3.8 & 25.0 & 3.8 & $>0.05$ \\
\hline Fatigue Severity Scale & 48.8 & 8.7 & 48.0 & 8.5 & 50.2 & 9.1 & $>0.05$ \\
\hline Fatigue Impact Scale & 92.2 & 26.2 & 92.6 & 24.6 & 91.6 & 29.2 & $>0.05$ \\
\hline HADS_A & 9.6 & 3.4 & 9.3 & 3.1 & 10.1 & 3.9 & $>0.05$ \\
\hline HADS_D & 8.5 & 3.1 & 8.5 & 3.0 & 8.6 & 3.4 & $>0.05$ \\
\hline $\mathrm{BDI}$ & 17.6 & 8.1 & 18.3 & 8.3 & 16.4 & 7.9 & $>0.05$ \\
\hline Epworth Sleepiness Scale & 10.3 & 5.6 & 10.6 & 5.3 & 9.8 & 6.2 & $>0.05$ \\
\hline Quality of Life Scale & 63.5 & 10.9 & 62.1 & 11.9 & 65.9 & 8.8 & $>0.05$ \\
\hline Orthostatic Grading Scale & 8.4 & 3.1 & 3.5 & 3.4 & 3.4 & 2.5 & $>0.05$ \\
\hline
\end{tabular}


Table 4 Cardiovascular/autonomic parameters

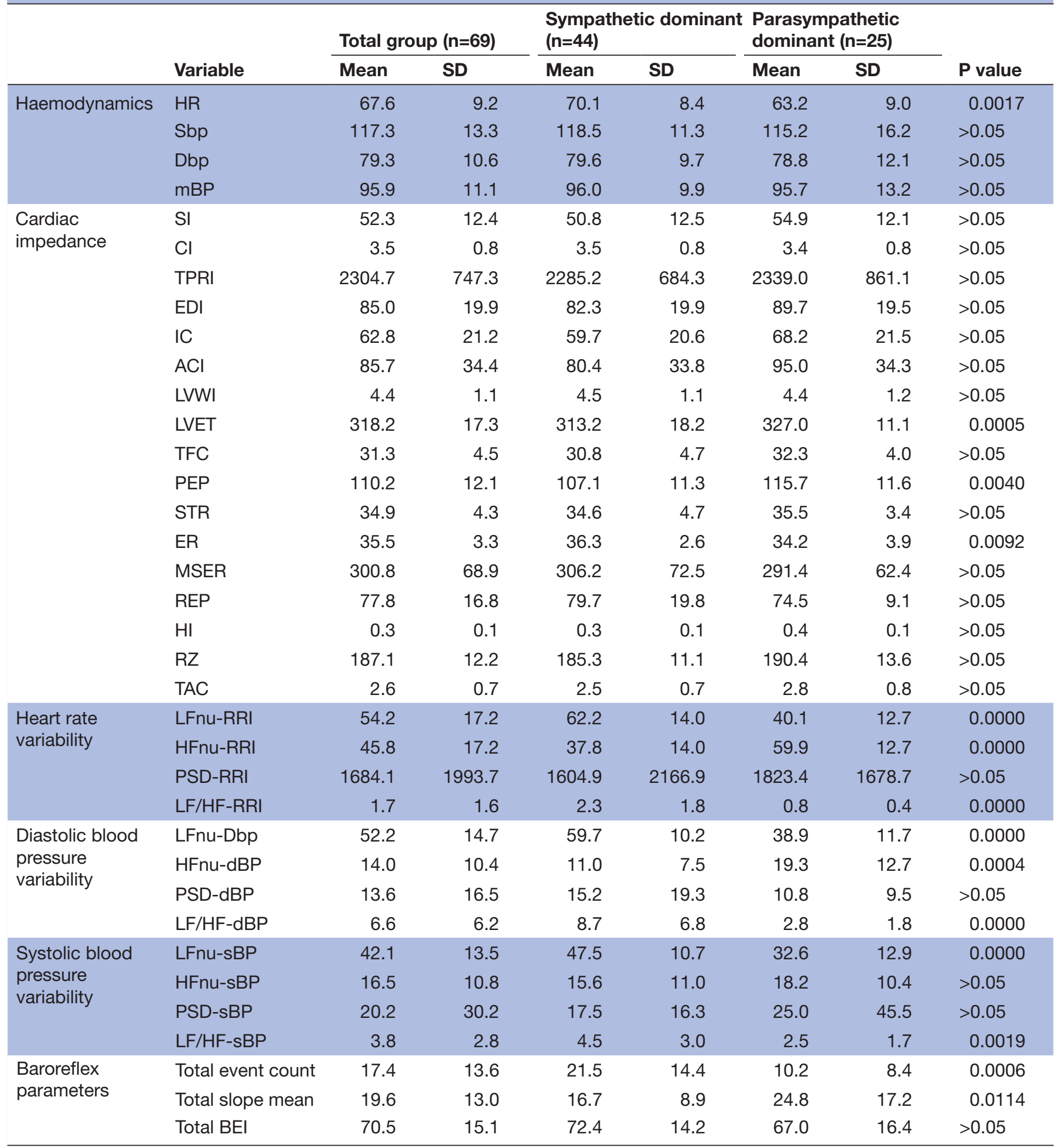

phenotypes with increased LF BPV in both diastolic and systolic blood pressure, reduced baroreflex sensitivity in those with the sympathetic dominant phenotype (table 4).

Those with the parasympathetic predominant phenotype were more likely to have had the disease for between 5 and 10 years (table 5 ).
Prevalence of postural tachycardia syndrome in a Polish cohort of CFS/ME patients

The presence of PoTS is frequently seen in those with CFS. ${ }^{28} 29$ A total of $35(51 \%)$ of the CFS group had haemodynamic responses to standing consistent with a diagnosis of PoTS. There was no difference in the proportion of those with PoTS in the sympathetic or parasympathetic groups (table 5). 
Table 5 PoTS (sympathetic, $\mathrm{N}=44$; parasympathetic, $\mathrm{N}=25$ )

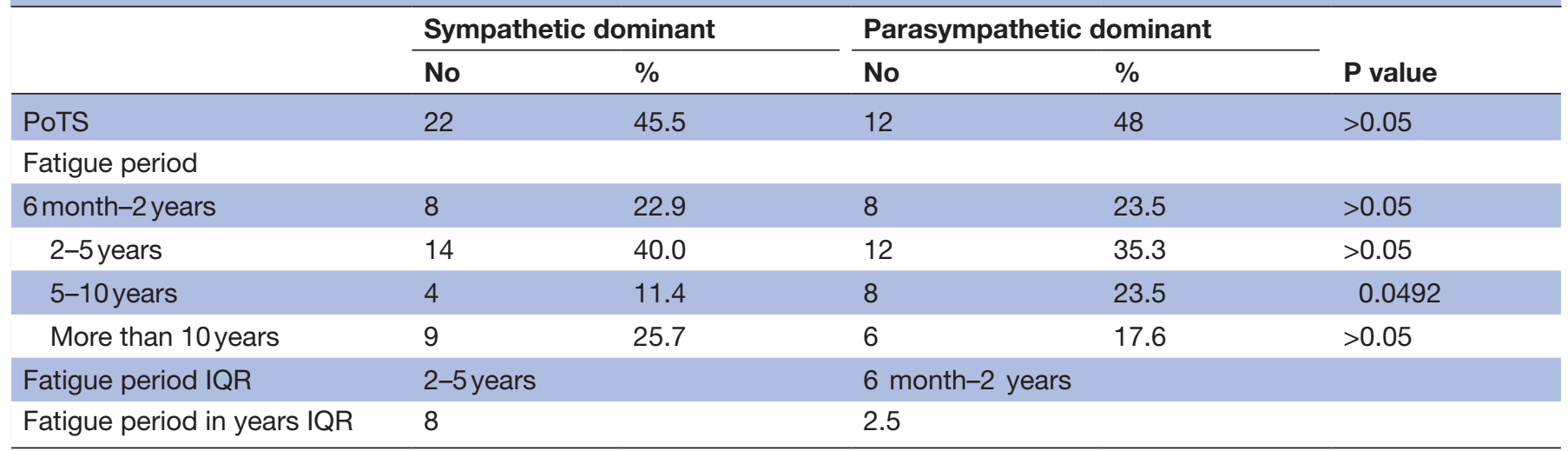

PoTS, postural tachycardia syndrome.

\section{DISCUSSION}

This study has confirmed for the first time that chronic fatigue is a common symptom experienced by the Polish population and that CFS/ME is an under-recognised syndrome in this group. The key finding of this study is that prevalence is similar to reported data in the other countries and is associated with a large symptom burden and impaired quality of life.

Of the cohort of 1400 who self-presented with fatigue only 69 subsequently were confirmed as having CFS/ME using the Fukuda criteria. This suggests that in Poland there are significant amounts of fatigue related to other conditions, with only a small percentage of those experiencing fatigue having CFS/ME per se (69/1400; $5 \%)$.

From the initial responses, we rigorously identified those who met with Fukuda criteria for CFS/ME. We did this by asking individuals to complete the tool, but also using face to face sessions with trained clinicians. We believe therefore, that our cohort represents a well characterised group who we are confident fulfil one of the recognised diagnostic criteria for CFS/ME. When we compared this Polish cohort with CFS/ME to other national cohorts there were some similarities, but also some differences.

Compared with the UK cohort ${ }^{30}$ having in excess of 6500 individuals collected from the UK NHS Clinical CFS services, the Polish cohort appeared to be of a similar age to the UK cohort with comparable levels of fatigue and illness duration, have similar levels of sleep and cognitive symptoms but less postexertional malaise, muscle pain and headaches. The Polish cohort appeared to have more males than was seen in the UK cohort.

As in previous national cohorts, ${ }^{3} 30$ the presence of fatigue in the Polish population was associated with impaired quality of life. As has been seen previously, impaired quality of life associates with the severity of symptoms such as fatigue and autonomic dysfunction, but in contrast to other studies, not daytime sleepiness. Impaired quality of life is also associated with increased anxiety and more depression. As in other series, we would suggest that this association is a secondary phenomenon that is, arising as a consequence of the condition rather than a cause. The fact that we rigorously excluded depression and psychiatric disorders when determining the criteria would be consistent with this.

Our study has also confirmed a high prevalence of the condition PoTS. This form of dysautonomia ${ }^{21}$ has been recognised as occurring frequently in those with CFS/ $\mathrm{ME},{ }^{28}{ }^{29}$ and represents a potential therapeutic target in those with this illness. It is important that clinicians and researchers are aware of the overlap and are trained to identify and manage this condition.

All of these differences might arise because of the self-report nature of the Polish cohort and that the UK cohort was recruited from the National Health Service clinical services which were specifically set up to identify and manage CFS/ME. ${ }^{3}$ A comprehensive review of the prevalence of CFS/ME in three regions of England involving 143000 subjects suggested an older cohort with longer disease duration than that seen in the UK clinical services.

An Australian cohort $^{31}$ was established using similar identification strategies to our Polish cohort with self-report in response to adverts inviting individuals to participate in a research database. Individuals in this cohort were included if they had received the diagnosis from a primary care physician. Again the proportion of females in the Australian cohort was higher than in the Polish cohort

This study has a number of limitations. The case ascertainment process used self-report as the means of identifying those with CFS/ME. It became clear during the radio and television campaign that there was considerable interest, and as a result our recruitment process needed to be changed to facilitate timely screening of those self-presenting with fatigue. It is clear that a thorough, methodologically robust epidemiological study of fatigue and its consequences in a Polish population are now needed.

Our study has confirmed that fatigue is a common and under-recognised symptom affecting the Polish population. It impacts on quality of life and is associated with 
a range of other symptoms that have been previously recognised in other cohort studies. Despite this, there are no clinical services for fatigue or CFS/ME in Poland and it is poorly understood and infrequently diagnosed. Our research programme now aims to consider the effect of interventions on fatigue in a Polish CFS/ME population.

Contributors JS, DS, SM-G and PZ were involved in writing of the manuscript. JS, $P Z$, JK and MT-K conceived and supervised the study. SK and PZ provided statistical advice. JS, PZ, JLN, DS and SM-G contributed conceived, designed and performed the experiments, collected and analyzed the data, revising it critically for important intellectual content and final approval of the version to be submitted.

Funding The authors have not declared a specific grant for this research from any funding agency in the public, commercial or not-for-profit sectors.

Competing interests None declared.

Patient consent for publication Obtained.

Ethics approval The study was approved by the Ethics Committee, Ludwik Rydygier MemorialCollegium Medicum in Bydgoszcz, Nicolaus Copernicus University, Torun.

Provenance and peer review Not commissioned; externally peer reviewed.

Data sharing statement No additional data are available.

Open access This is an open access article distributed in accordance with the Creative Commons Attribution Non Commercial (CC BY-NC 4.0) license, which permits others to distribute, remix, adapt, build upon this work non-commercially, and license their derivative works on different terms, provided the original work is properly cited, appropriate credit is given, any changes made indicated, and the use is non-commercial. See: http://creativecommons.org/licenses/by-nc/4.0/.

\section{REFERENCES}

1. NICE. Chronic Fatigue Syndrome/Myalgic Encephalomyelitis (encephalopathy); diagnosis and management. www.nice.gov.org.

2. Institute of Medicine. Beyond Myalgic Encephalomyelitis/Chronic Fatigue Syndrome Redefining an Illness Committee on the Diagnostic Criteria for Myalgic Encephalomyelitis/Chronic Fatigue Syndrome; Board on the Health of Select Populations; Institute of Medicine. Washington (DC): National Academies Press (US), 2015. ISBN-13: 978-0-309-31689-7ISBN-10: 0-309-31689-8.

3. Nacul LC, Lacerda EM, Pheby D, et al. Prevalence of myalgic encephalomyelitis/chronic fatigue syndrome (ME/CFS) in three regions of England: a repeated cross-sectional study in primary care. BMC Med 2011;9:91.

4. Fukuda K. The chronic fatigue syndrome: a comprehensive approach to its definition and study. Ann Intern Med 1994;121:953-9.

5. Chalder T, Berelowitz G, Pawlikowska T, et al. Development of a fatigue scale. J Psychosom Res 1993;37:147-53.

6. Morriss RK, Wearden AJ, Mullis R. Exploring the validity of the Chalder Fatigue scale in chronic fatigue syndrome. $J$ Psychosom Res 1998;45:411-7.

7. De Vries J, Michielsen HJ, Van Heck GL. Assessment of fatigue among working people: a comparison of six questionnaires. Occup Environ Med 2003;60(Suppl 1):10i-15.

8. Zigmond AS, Snaith RP. The hospital anxiety and depression scale. Acta Psychiatr Scand 1983;67:361-70.

9. Johns MW. A new method for measuring daytime sleepiness: the Epworth sleepiness scale. Sleep 1991;14:540-5.
10. Suarez GA, Opfer-Gehrking TL, Offord KP, et al. The Autonomic Symptom Profile: a new instrument to assess autonomic symptoms. Neurology 1999;52:523-8.

11. Sletten DM, Suarez GA, Low PA, et al. COMPASS 31: a refined and abbreviated Composite Autonomic Symptom Score. Mayo Clin Proc 2012;87:1196-201.

12. Burckhardt CS, Woods SL, Schultz AA, et al. Quality of life of adults with chronic illness: a psychometric study. Res Nurs Health 1989;12:347-54.

13. Burckhardt CS, Clark SR, Bennett RM. Fibromyalgia and quality of life: a comparative analysis. J Rheumatol 1993;20:475-9.

14. Flanagan JC. Measurement of quality of life: current state of the art. Arch Phys Med Rehabil 1982;63:56-9.

15. Fortin J, Habenbacher W, Gruellenberger R, et al. Real time monitor for hemodynamic beat-to-beat parameters and power spectra analysis of biosignals. Hong Kong: Proceedings of the 20th annual International Conference of the IEEE Engineering in Medicine and Biology Society, 1998.

16. Fortin J, Th K, Ch W, et al. The Task Force Monitor-a non-invasive beat-to-beat monitor for hemodynamic and autonomic function of the human body. Hong Kong: Proceedings of the 20th annual International Conference of the IEEE Engineering in Medicine and Biology Society, 1998.

17. Fortin J, Marte W, Grüllenberger R, et al. Continuous non-invasive blood pressure monitoring using concentrically interlocking control loops. Comput Biol Med 2006;36:941-57.

18. Parati G, Ongaro G, Bilo G, et al. Non-invasive beat-to-beat blood pressure monitoring: new developments. Blood Press Monit 2003;8:31-6.

19. Bianchi AM, Mainardi LT, Meloni C, et al. Continuous monitoring of the sympatho-vagal balance through spectral analysis. IEEE Eng Med Biol Mag 1997;16:64-73.

20. Malik M, Bigger JT, Camm AJ, et al. Heart rate variability: Standards of measurement, physiological interpretation, and clinical use. Eur Heart J 1996; 17:354-81.

21. Stauss HM. Heart rate variability. Am J Physiol Regul Integr Comp Physiol 2003;285:R927-31.

22. Akselrod S, Gordon D, Madwed JB, et al. Hemodynamic regulation: investigation by spectral analysis. Am J Physiol 1985;249:H86 7-H875.

23. Frith J, Zalewski P, Klawe JJ, et al. Impaired blood pressure variability in chronic fatigue syndrome--a potential biomarker. QJM 2012;105:831-8.

24. Słomko J, Zawadka-Kunikowska M, Kujawski S, et al. Do changes in hemodynamic parameters depend upon length of sleep deprivation? comparison between subjects with normal blood pressure, prehypertension, and hypertension. Front Physiol 2018;9:1374

25. Sheldon RS, Grubb BP, Olshansky B, et al. Inappropriate sinus tachycardia, and vasovagal syncope. Heart Rhythm 2015;12:e41-e63 https://doi.org/.

26. Eckberg DL. Sympathovagal balance. A critical appraisal.

27. Malliani A, Pagani M, Montano N, et al. Sympathovagal balance: a reappraisal. Circulation 1998;98:2640-3.

28. Hoad A, Spickett G, Elliott J, et al. Postural orthostatic tachycardia syndrome is an under-recognized condition in chronic fatigue syndrome. QJM 2008;101:961-5.

29. Reynolds GK, Lewis DP, Richardson AM, et al. Comorbidity of postural orthostatic tachycardia syndrome and chronic fatigue syndrome in an Australian cohort. J Intern Med 2014;275:409-17.

30. Collin SM, Nuevo R, van de Putte EM, et al. Chronic fatigue syndrome (CFS) or myalgic encephalomyelitis (ME) is different in children compared to in adults: a study of UK and Dutch clinical cohorts. BMJ Open 2015;5:e008830.

31. Johnston SC, Staines DR, Marshall-Gradisnik SM. Epidemiological characteristics of chronic fatigue syndrome/ myalgic encephalomyelitis in Australian patients. Clin Epidemiol 2016;8:97-107. 